\title{
Revisión
}

\section{Péptidos antimicrobianos de organismos procariotas y eucariotas como agentes terapéuticos y conservantes de alimentos}

RECIBIDO: 13/10/2013

ACEPTADO: 25/10/2013

\section{Tonarelli, G. ${ }^{1} \cdot$ Simonetta, A. ${ }^{2}$}

1 Departamento Química Orgánica. Facultad de Bioquímica y Ciencias Biológicas de la Universidad Nacional del Litoral. Ciudad Universitaria. Paraje El Pozo s/n. 3000, Santa Fe, Argentina. Teléfono: 0342-4575206 (int. 224).

2 Dpto. de Ingeniería en Alimentos. Facultad de Ingeniería Química de la Universidad Nacional del Litoral. Teléfono: 0342-4571164 (int. 2541).

E-mail: asimonet@fiq.unl.edu.ar tonareli@fbcb.unl.edu.ar

RESUMEN: El uso indiscriminado de los antibióticos ha llevado a un rápido aumento de la resistencia de los microorganismos a estos compuestos convencionales y, en consecuencia, existe la necesidad de desarrollar nuevos fármacos.

Los péptidos antimicrobianos son componentes evolutivamente conservados de la respuesta inmune innata, y están presentes en bacterias, plantas y animales vertebrados e invertebrados, y son considerados como una nueva fuente natural de agentes terapéuticos. Por otra parte, las bacteriocinas han cobrado gran importancia debido a las posibilidades de su empleo en la biopreservación de alimentos, reemplazando a los conservantes químicos. Especial interés presentan las generadas por bacterias ácido lácticas, dado que tanto éstas como sus productos metabólicos son seguros para su incorporación a diferentes matrices alimentarias.

En este artículo se presentan los aspectos más relevantes sobre biodiversidad, estructura y aplicaciones en tecnologías de alimentos y en clínica médica de los péptidos antimicrobianos, y se consideran sus principales ventajas y desventajas.

PALABRAS CLAVE: Péptidos antimicrobianos, Bacteriocinas, Agentes terapéuticos, Biopreservadores alimentarios.

SUMMARY: Antimicrobial peptides of prokaryotic and eukaryotic organisms as therapeutic agents and food preservatives The widespread use of antibiotics has led to a rapid increase in the resistance of 
microorganisms to conventional antibiotics, and therefore there is a need to develop new drugs. Antimicrobial peptides are evolutionarily conserved components of the innate immune response and are present in bacteria, plants, vertebrates and invertebrates, and are considered as a new natural source of therapeutic agents. Moreover, bacteriocins have gained great importance due to their potential use in food biopreservation, replacing chemical preservatives. Of particular interest are those generated by lactic acid bacteria, since they and their metabolic products are safe for incorporation into different food matrices. In this article we present the most relevant aspects of biodiversity, structure and applications in food technology and medical clinic of antimicrobial peptides, and their main advantages and disadvantages are considered.

KEYWORDS: Antimicrobial peptides, Bacteriocins, Therapeutic agents, Food Biopreservatives.

\section{Introducción}

La Organización Mundial de la Salud (OMS) considera que la resistencia antimicrobiana es una de las amenazas más importantes para la salud humana, la cual surge por mutación del microorganismo o adquisición de genes de resistencia. Un alto porcentaje de infecciones hospitalarias se deben a bacterias muy resistentes, como Staphylococcus aureus resistente a la meticilina. El uso inadecuado de los antibióticos crea condiciones favorables a la aparición, propagación y persistencia de microorganismos resistentes (Organización Mundial de la Salud, http: //www.who.int/ mediacentre/factsheets/fs194). Esto evidencia la necesidad de la búsqueda de nuevas opciones que permitan sustituir a los antibióticos convencionales.

Si bien se han desarrollado nuevas tecnologías para el descubrimiento de fármacos, la naturaleza sigue siendo el punto de partida más importante para el desarrollo de nuevos agentes terapéuticos (1-3).

En particular, en el caso de los antimicrobianos sólo el $20 \%$ de los productos comer- cializados son totalmente sintéticos, en otras palabras no fueron inspirados en productos naturales (4).

Los péptidos antimicrobianos (PAs) constituyen una característica universal de los sistemas de defensa de prácticamente todas las formas de vida y se han encontrado en diferentes organismos, desde bacterias, plantas, aves, peces, insectos, anfibios y mamíferos.

Estos compuestos contienen entre $12 \mathrm{y}$ 50 aminoácidos, y no solamente destruyen diferentes bacterias, sino también varios hongos, parásitos y células cancerosas (5).

Son considerados importantes moléculas efectoras del sistema inmune innato, el cual es el principal mecanismo de defensa para la mayoría de los organismos vivos durante las etapas iniciales de una infección, y complementan al altamente específico sistema inmune adaptativo $(6,7)$.

La expresión de los PAs puede ser constitutiva o puede ser inducida en respuesta a estímulos infecciosos y/o inflamatorios, tales como bacterias o moléculas presentes en esas bacterias que inducen la inmunidad 